\title{
Adaptation of methods for glutamate dehydrogenase and alcohol dehydrogenase activities to a centrifugal analyser: assessment of their clinical use in anoxic states of the liver
}

\author{
M D S SHEPHARD, L A PENBERTHY, M N BERRY \\ From the Department of Biochemistry and Chemical Pathology, Flinders Medical Centre, Bedford Park, South \\ Australia
}

SUMMARY Sensitive, precise, and rapid methods for the measurement of alcohol dehydrogenase (ADH) and glutamate dehydrogenase (GDH) were developed on the Cobas Bio centrifugal anal $-\mathbb{N}$ yser. The optimal $\mathrm{pH}$ for ADH in caucasians was $9 \cdot 8$. Non-linearity of ADH enzyme activity was observed when samples were diluted in saline; linearity was restored when inactivated serum was? used as diluent. ADH was shown to be a sensitive index of liver anoxia due to cardiorespiratoryo disturbance (clinical sensitivity $90 \%$ ) and generalised anoxia. GDH exhibited sensitivity equal too that of alanine aminotransferase (ALT) but was inferior to gamma-glutamyltransferase (GGT) in the detection of specific liver disease. Both ADH and GDH were sensitive indicators of alcoholic liver disease.

Alcohol dehydrogenase (ADH, EC 1.1.1.1) is a cytoplasmic liver enzyme located predominantly in the centrilobular region of the liver (zone 3 of the hepatic acinus); glutamate dehydrogenase (GDH, EC 1.4.1.2) is predominantly a liver enzyme found in mitochondria. Until recently critical assessment of the diagnostic potential of these two enzymes was limited by (i) their very low activity in normal human serum and (ii) the lack of sensitive spectrophotometric assay techniques to measure their activities.

Several recent reports document differing and often conflicting clinical uses for these enzymes. Fujisawa $e t$ $a l^{1}$ stated that ADH is a sensitive marker for chronic hepatitis and chronic aggressive hepatitis, but not for obstructive jaundice. Khayrollah et $a l^{2}$ concluded that ADH is a sensitive indicator for assessing hepatotoxicity due to drugs, hepatocellular damage, infection, inflammation and malignancy. More recently, Kato et $\mathbf{~ a l}^{\mathbf{3} 4}$ stated that ADH activity may be raised in patients with hepatic centrilobular damage. Glutamate dehydrogenase was shown by Jung et al ${ }^{5}$ to be of similar diagnostic sensitivity to mitochondrial aspartate aminotransferase (AST, EC 2.6.1.1) in chronic pathological liver states. Schellenberg et $a l^{6}$

Accepted for publication 4 March 1987 stated that the place of GDH in the laboratory was $\operatorname{tn}$ the detection of heavy drinkers. Levy ${ }^{7}$ concluded that GDH was useful as a cancer marker in hepatic meta stases, while Kim et $a l^{8}$ showed that, although GDH㐫 was as sensitive and specific as serum alkaline phos $\stackrel{\overrightarrow{7}}{\overrightarrow{7}}$ phatase activity (AP, EC 3.1.3.1) in the detection of hepatic metastases, it was inferior to gammaglutamyltransferase (GGT, EC 2.3.2.2) and $5^{\prime}$-nucleotidase (5'NT, EC 3.1.3.5).

This paper describes the development of sensitiveo routine methods for the measurement of GDH ando ADH using a centrifugal analyser. For GDH, a man ual kit procedure was adapted for use with the centrif-o ugal analyser. A method for ADH using centrifugaR analysis has recently been reported by $\mathrm{Kato}^{3}$ in Japan. As racial differences in ADH activity, caused $>$ by isoenzyme heterogeneity have been documented, $\stackrel{\text { OO }}{=}$ we modified this method and optimised reaction conditions for a caucasian population.

The clinical use of these enzymes was examined in several selected patient groups, with particular atten tion being focused on those conditions which may, as a result of primary cardiorespiratory disturbanceso lead to centrilobular necrosis. Alanine aminotransferase (ALT, EC 2.6.1.2) and gamma? glutamyltransferase activities were measuredo concurrently for comparative purposes. 
Material and methods

GLUTAMATE DEHYDROGENASE

A Boehringer Mannheim kit, BM Test-Combination GLDH activated (Boehringer Mannheim, Mannheim, West Germany; catalogue number 124 320) was used in this study. The kit comprises three reagent phials; phial 1-triethanolamine buffer $(50 \mathrm{mmol} / \mathrm{l}$, $\mathrm{pH} 8.0$ ) containing ammonium acetate and edetic acid at final concentrations of $0.1 \mathrm{~mol} / 1$ and 2.5 $\mathrm{mmol} / \mathrm{l}$, respectively; phial 2-ADP and reduced nicotine adenine dinucleotide (NADH) at final concentrations of $1 \mathrm{mmol} / 1$ and $0.2 \mathrm{mmol} / 1$, respectively; and phial 3 containing $\alpha$-oxoglutarate, $7 \mathrm{mmol} / \mathrm{l}$ final concentration. The contents of phial 2 were dissolved in $1.5 \mathrm{ml}$ of buffer from phial 1 . Working reagent was then prepared by mixing 1 volume from phial 2 with 25 volumes from phial 1. Phial 3 containing substrate was added to the working reagent separately to start the reaction. GDH catalyses the conversion of oxoglutarate in the presence of ammonium ions to glutamate, with concomitant oxidation of NADH to nicotine adenine dinucleotide $\left(\mathrm{NAD}^{+}\right)$, which can be measured spectrophotometrically at $340 \mathrm{~nm}$.

\section{ALCOHOL DEHYDROGENASE}

The assay for ADH was based on that described by Kato. ${ }^{3}$ Reagents used were (i) glycine-NaOH buffer, $0.1 \mathrm{~mol} / \mathrm{l}$; (ii) NAD (Boehringer Mannheim, Mannheim, West Germany; catalogue No 127990, grade II, free acid, $5 \mathrm{~g}$ ), $10 \mathrm{mmol} / 1$ in distilled water and prepared fresh each day; and (iii) ethanol, $20 \mathrm{mmol} / \mathrm{l}$. Working reagent was prepared by adding $2 \mathrm{ml}$ of NAD solution to $10 \mathrm{ml}$ of buffer. Ethanol was added as a start reagent. ADH catalyses the conversion of ethanol to acetaldehyde with simultaneous reduction of NAD to NADH.

\section{ALANINE AMINOTRANSFERASE}

ALT was measured by the method recommended by the International Federation of Clinical Chemistry (IFCC) ${ }^{10}$ (without activator) using a Roche Diagnostica kit (Roche Products Ltd, Dee Why, New South Wales, Australia) (catalogue No 071404) on the Cobas Bio centrifugal analyser (Roche Analytical Instruments, Nutley, New Jersey, United States of America).

\section{GAMMA GLUTAMYLTRANSFERASE}

GGT was also measured on the Cobas Bio by a Roche Diagnostica kit (catalogue No 07 14259) using the method of Szasz. ${ }^{11}$

\section{Results}

\section{ADAPTATION OF GDH ASSAY TO COBAS BIO CENTRIFUGAL ANALYSER \\ Reaction kinetics}

Reaction kinetics of the GDH assay were monitored for 900 seconds with the instrument settings shown in table 1. For patient samples with GDH activity of 100 $\mathrm{U} / \mathrm{l}$ or less, the reaction was linear throughout the time interval measured.

\section{Selection of optimised reaction conditions}

In view of the observed linearity a minimum preincubation time of reagent of 10 seconds was considered to be suitable for the assay. To keep the total analysis time to roughly five minutes, an initial reading was taken 60 seconds after addition of sample and

Table 1 Reaction conditions on Cobas Bio for measurement of GDH and ADH

\begin{tabular}{|c|c|c|c|c|c|c|}
\hline & Instrument settings & $\begin{array}{l}\text { GDH kinetic } \\
\text { studies }\end{array}$ & $\begin{array}{l}\text { GDH final assay } \\
\text { conditions }(20 \mu l)\end{array}$ & $\begin{array}{l}\text { ADH assay pH } \\
\text { optimum studies }\end{array}$ & $\begin{array}{l}\text { ADH kinetic } \\
\text { studies }\end{array}$ & $\begin{array}{l}\text { ADH final } \\
\text { assay } \\
\text { conditions }\end{array}$ \\
\hline 1 & Units & $\mathrm{U} / \mathbf{1}$ & $\mathrm{U} / 1$ & $\mathrm{U} / \mathbf{1}$ & $\mathbf{U} / \mathbf{1}$ & $\mathrm{U} / \mathbf{l}$ \\
\hline 2 & Calculation factor & 1984 & 1984 & 1323 & 1323 & 1323 \\
\hline 3 & Standard 1 concentration & 0 & 0 & 0 & 0 & 0 \\
\hline 4 & Standard 2 concentration & 0 & 0 & 0 & 0 & 0 \\
\hline 5 & Standard 3 concentration & 0 & 0 & $\mathbf{0}$ & 0 & 0 \\
\hline 6 & Limit & $\mathbf{0}$ & 0.252 & 0 & 0 & 0.185 \\
\hline 7 & Temperature $\left({ }^{\circ} \mathrm{C}\right)$ & $37 \cdot 0$ & $37 \cdot 0$ & $37 \cdot 0$ & $37 \cdot 0$ & $37 \cdot 0$ \\
\hline 8 & Type of analysis & 3 & 3 & 3 & 3 & 3 \\
\hline 9 & Wavelength (nm) & 340 & 340 & 340 & 340 & 340 \\
\hline 10 & Sample volume $(\mu \mathrm{l})$ & 20 & 20 & 30 & 30 & 30 \\
\hline 11 & Diluent volume $(\mu \mathrm{l})$ & 30 & 30 & 40 & 40 & 40 \\
\hline 12 & Reagent volume $(\mu \mathrm{l})$ & 250 & 250 & 300 & 300 & 300 \\
\hline 13 & Incubation time (seconds) & 10 & 10 & 300 & 10 & 120 \\
\hline 14 & Start reagent volume $(\mu \mathrm{l})$ & 10 & 10 & 10 & 10 & 10 \\
\hline 15 & Time of first reading & & & & & \\
\hline & (seconds) & 0.5 & 60 & 20 & 0.5 & 0.5 \\
\hline 16 & Time intervals (seconds) & 30 & 10 & 10 & 30 & 10 \\
\hline 17 & No of readings & 30 & 24 & 20 & 30 & 18 \\
\hline 18 & Blanking mode & 1 & 1 & 1 & 1 & 1 \\
\hline 19 & Printout mode & 1 & $i$ & 1 & 1 & 2 \\
\hline
\end{tabular}


the reaction was then monitored for a further $240 \mathrm{sec}-$ onds. Printout mode 1 (assessment of the linear part of the reaction curve) was found to be superior to printout mode 2 (assessment of all points on the reaction curve by linear regression) for data reduction as mode 2 recorded several noise flags with patient material. Table 1 lists the final instrument settings for this assay system.

\section{Precision studies}

Three patients' sera with low, moderate, and raised GDH activity $(8,45$, and $160 \mathrm{U} / 1$, respectively) were selected for both intrarun and interrun precision studies of the assay. Samples to be analysed for interrun precision were stored at $-70^{\circ} \mathrm{C}$. Table 2 summarises the results and shows that both assays are precise, with coefficients of variation at all levels of $5.1 \%$ or less.

\section{Linearity}

Serial dilutions were prepared from a patient sample with GDH activity of $750 \mathrm{U} / 1$ and used to assess the linearity of each method. The assay was linear up to $500 \mathrm{U} / 1$.

\section{Reference range}

Serum from 100 apparently healthy subjects, all of whom had normal ALT activities, was used to derive a reference range for GDH. Data were processed using non-parametric statistics. The reference range for GDH was calculated as 0-5 U/l.

\section{Stability}

A trial to assess GDH stability was conducted. Three samples with low $(5 \mathrm{U} / \mathrm{l})$, moderate $(50 \mathrm{U} / \mathrm{l})$, and high $(150 \mathrm{U} / \mathrm{l}) \mathrm{GDH}$ activity were stored at $4^{\circ} \mathrm{C},-20^{\circ} \mathrm{C}$, and $-70^{\circ} \mathrm{C}$ for one week. All samples, independent of their activity, were stable over the week when stored at $-70^{\circ} \mathrm{C}$. Results obtained for storage at $4^{\circ} \mathrm{C}$ and $-20^{\circ} \mathrm{C}$ were similar and showed that for the low sample GDH activity was stable for $\mathbf{4 8}$ hours, while for the moderate and high samples, on average, $5 \%$ activity was lost each day, that is, after one week, there was nearly a $40 \%$ reduction in initial activity.

\section{MODIFICATION AND OPTIMISATION OF ADH ASSAY ON COBAS BIO Determination of $\mathrm{pH}$ optimum}

In a study of Japanese subjets Kato determined the $\mathrm{pH}$ optimum for $\mathrm{ADH}$, using glycine- $\mathrm{NaOH}$ buffer, to be $9 \cdot 0^{3}$; however, the author qualified this finding by stating that the $\mathrm{pH}$ optimum would need to be redetermined for caucasians.

Using the assay conditions of Kato (table 1) buffers with $\mathrm{pH}$ of $8 \cdot 0,9 \cdot 0,10 \cdot 0,10 \cdot 5$ and 11.0 were prepared. A selection of patient samples were analysed using

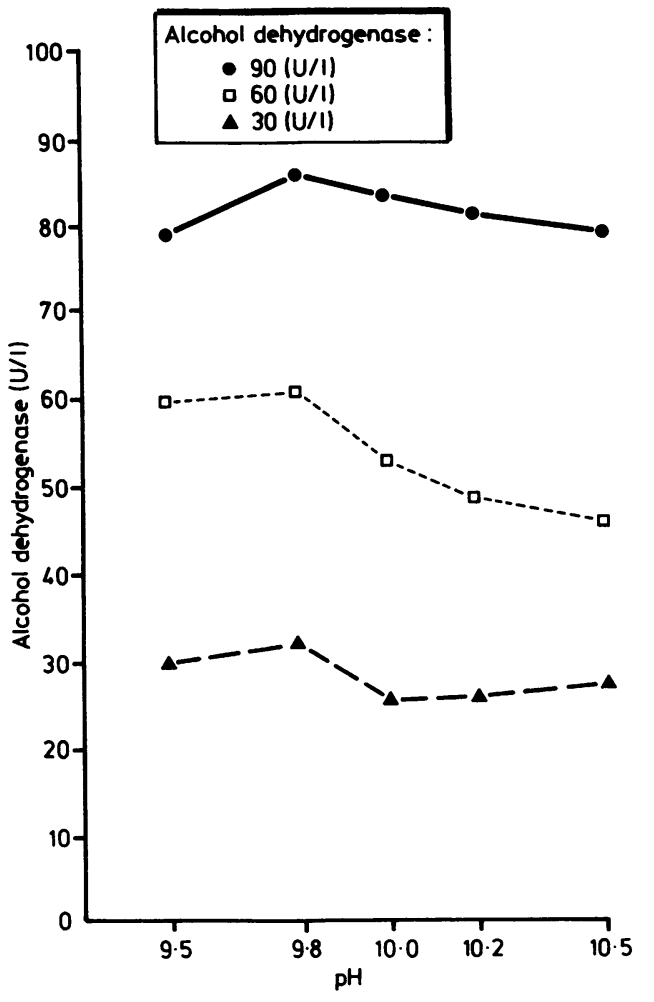

Fig 1 Determination of $p H$ optimum for $A D H$ in caucasid? population

this range of buffers to determine an approximate $\mathrm{pH} \stackrel{\overline{\overline{0}}}{\exists}$ optimum. From this preliminary experiment, optimum ADH activity was observed at $\mathrm{pH} 10 \cdot 0$. As a result, further buffers with pH's of 9.5, 9.8, 10.0 and 10.5 were prepared for detailed investigation.

In each of four separate experiments three differento patient samples, each with ADH activities of about 30,60 , and $90 \mathrm{U} / 1$, were assayed with this range of buffers. Fig 1 shows representative data from one $₹$ such experiment. While there was little difference in을 $\mathrm{pH}$ optimum between $\mathrm{pH} 9.5$ and 9.8 at low $\mathrm{ADH}_{\supset}$ activity, it was clearly evident that the $\mathrm{pH}$ optimum for the caucasian population was $9 \cdot 8$ at highern enzyme activity.

\section{Examination of reaction kinetics}

The reaction kinetics of the ADH assay, using the instrument settings shown in table 1 , were examinedo using a series of patient samples with $\mathrm{ADH}$ activities of 250,150 , or $35 \mathrm{U} / \mathrm{l}$ (fig 2 ). It was concluded that the? five minute preincubation time recommended byo $\mathrm{Kato}^{3}$ could be reduced to 120 seconds. As substrate 

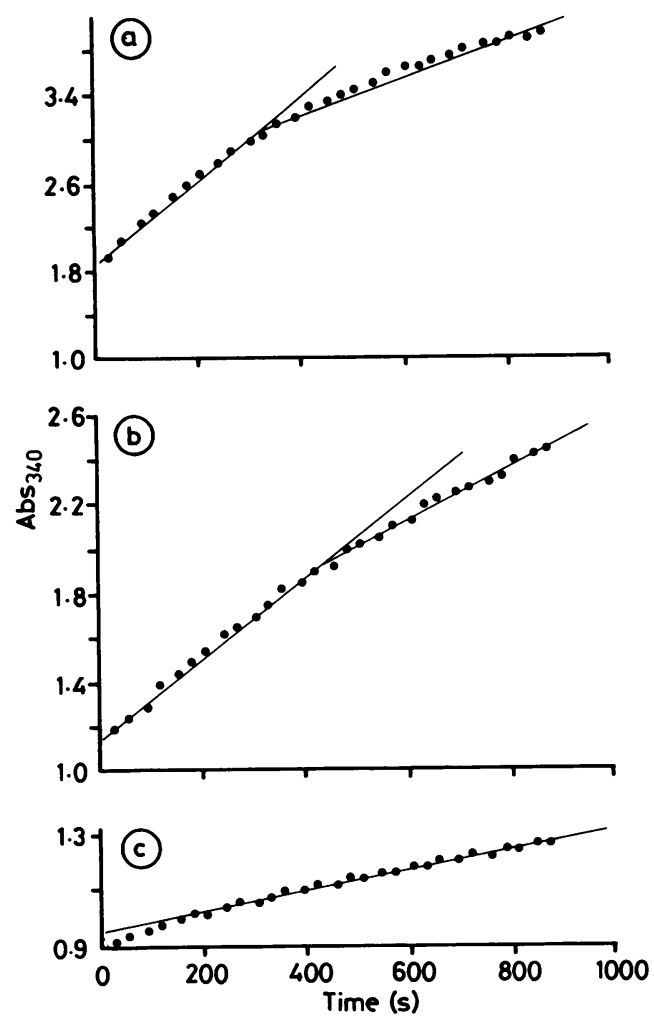

Fig 2 Reaction kinetics of ADH assay. ADH activity in these samples was a) $250 \mathrm{U} / \mathrm{l}, \mathrm{b}) 150 \mathrm{U} / \mathrm{l}$, and c) $35 \mathrm{U} / \mathrm{l}$.

depletion occurred after 360 seconds with ADH samples greater than $250 \mathrm{U} / 1$, a reading interval of 180 seconds (18 readings at 10 second intervals) was selected for our assay system. Total analysis time was therefore five minutes. Activities were calculated using lincar regression (printout mode 2). Table 1 lists final instrument settings for the ADH assay.

\section{Linearity}

Two patient samples, with activities of 400 and 35 $\mathrm{U} / \mathrm{l}$, respectively, were each diluted serially in saline and analysed on the Cobas Bio. Non-linearity was observed with both samples and was more exaggerated in the dilution of the low sample. A similar finding has been reported by the authors ${ }^{12}$ in studies with intestinal alkaline phosphatase, when a sample of high activity was diluted in saline. The two ADH samples were serially diluted in inactivated serum (prepared by heating serum at $65^{\circ} \mathrm{C}$ for 10 minutes). In contrast to the results found using saline as diluent, linearity was observed in both samples using the serum based diluent (fig 3). A repeat of the linearity experiment using a further patient sample (total activity $480 \mathrm{U} / 1$ ) diluted with inactivated serum confirmed that the linear range of the $\mathrm{ADH}$ assay was $0-250 \mathrm{U} / \mathrm{l}$.

Table 2 Precision studies for GDH assay using patient sera with low, moderate, and high GDH activity

\begin{tabular}{lllc}
\hline & Low & Moderate & High \\
\hline Intrarun precision: & & & \\
Mean & $7 \cdot 3$ & $45 \cdot 8$ & $160 \cdot 9$ \\
SD & $0 \cdot 15$ & $0 \cdot 59$ & $1 \cdot 20$ \\
CV\% & $2 \cdot 0 \%$ & $1 \cdot 3 \%$ & $0 \cdot 7 \%$ \\
$(\mathrm{n}=)$ & 10 & 10 & 10 \\
Interrun precision: & 6.9 & & \\
Mean & $6 \cdot 9$ & $44 \cdot 5$ & $155 \cdot 7$ \\
SD & $0 \cdot 27$ & $0 \cdot 30$ & $1 \cdot 25$ \\
CV\% & $3.9 \%$ & $0 \cdot 7 \%$ & $0 \cdot 8 \%$ \\
(n=) & 10 & 10 & 10 \\
\hline
\end{tabular}
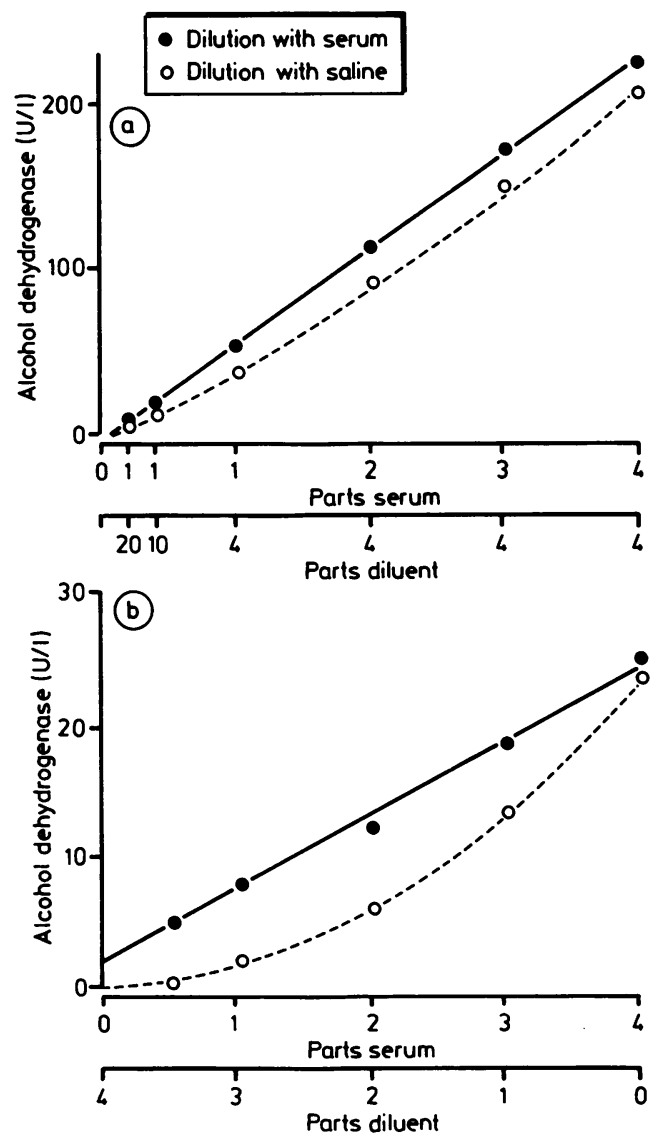

Fig 3 Linearity studies: differences observed using saline and inactivated serum as diluent. ADH activity in these samples was a) $400 U / l$, and b) $25 U / l$. 
Table 3 Precision studies for ADH assay using patient sera with low, moderate, and high GDH activity

\begin{tabular}{lllc} 
& Low & Moderate & High \\
\hline Intrarun precision: & $4 \cdot 7$ & & \\
Mean & 0.45 & 38.9 & $115 \cdot 1$ \\
SD & $1.0 \%$ & 0.40 & 0.71 \\
CV\% & 10 & $1.02 \%$ & $0.6 \%$ \\
(n=) & & 10 & 10 \\
Interrun precision: & $8 \cdot 7$ & & \\
Mean & 0.35 & $45 \cdot 7$ & 132.0 \\
SD & $4.0 \%$ & 1.35 & 1.82 \\
CV\% & 10 & $3.0 \%$ & $1.4 \%$ \\
(n=) & 10 & 10 & 10 \\
\hline
\end{tabular}

Precision studies

Intrarun and interrun precision data were obtained using different patient sera with low, moderate, ando raised activities of ADH. Table 3 summarises the results. Precision recorded using this assay system was superior to that documented by Kato. ${ }^{3}$

Reference range

From a population of 70 apparently healthy subjects, $\stackrel{\widehat{D}}{\stackrel{2}{\circ}}$ a reference range of $0-7 \mathrm{U} / 1$ for $\mathrm{ADH}$ was calculated $\tilde{\omega}$ using non-parametric statistics. This compares favourably with the range of $0-5 \mathrm{U} / 1$ determined by Kato. $^{3}$
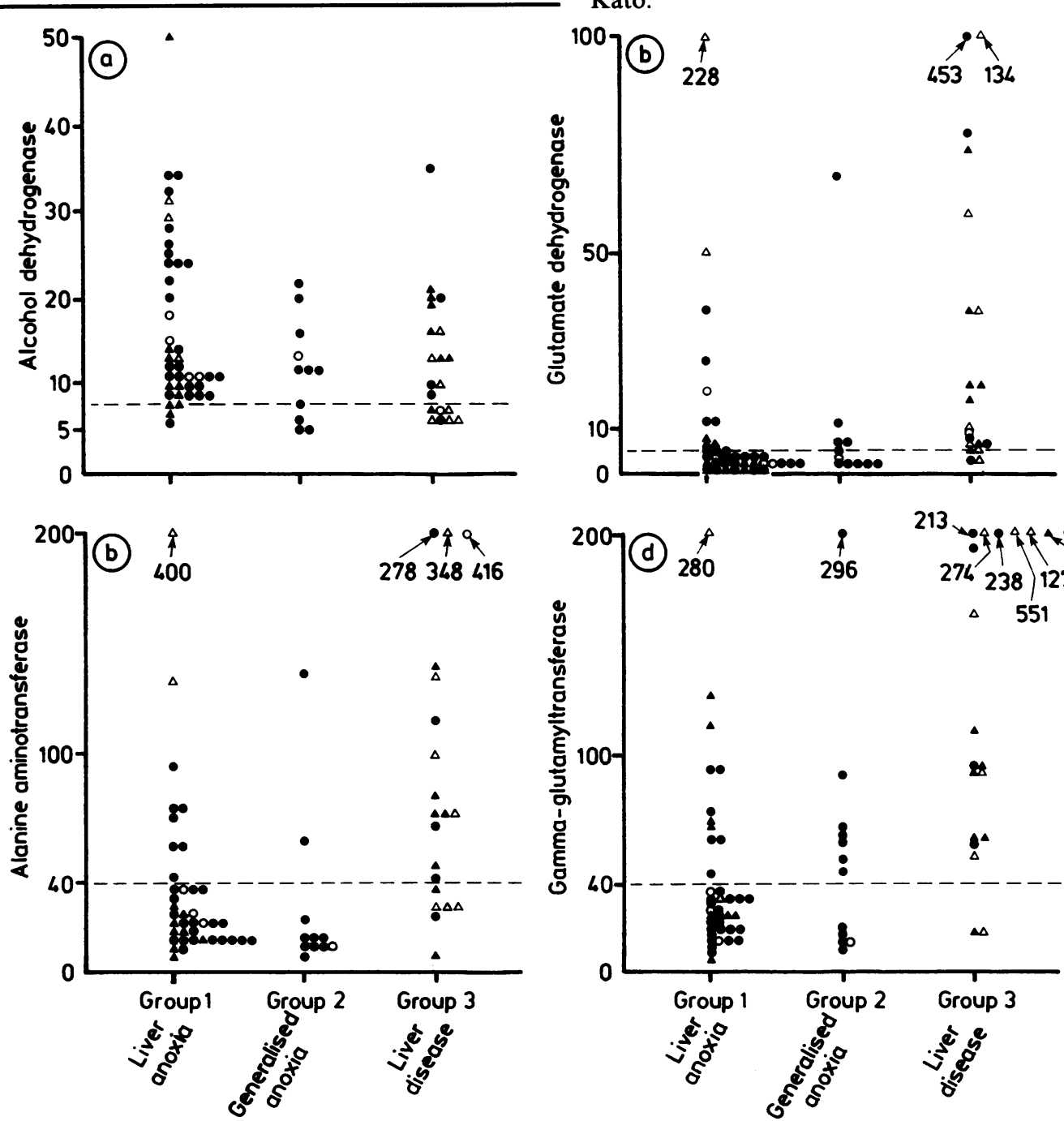

Fig 4 Activities of $A D H, G D H, A L T$ and $G G T$ (U/l) found in selected patient groups. Group 1: liver anoxia (centrilobular damage) due to congestive cardiac failure ( () , left ventricular failure ( $\bigcirc)$, chronic obstructive airways disease ( $\Delta$ ), or pulmonary oedema $(\triangle)$; Group 2: generalised anoxia, postoperatively ( $)$ ), or due to trauma ( $O$ ); Group 3: liver disease due to obstructive jaundice or cirrhosis $(\mathcal{O})$, viral hepatitis $(O)$, alcoholic liver disease $(\Delta)$ or carcinoma $(\Delta)$. 
Table 4 Summary of clinical sensitivity of $A D H, G D H$, $A L T$, and $G G T$ in specific diseases or groups

\begin{tabular}{llllll}
\hline & & \multicolumn{3}{c}{ Clinical sensitivity (\%) } \\
\cline { 3 - 6 } $\begin{array}{l}\text { Group/ } \\
\text { subgroup }\end{array}$ & Disease & $A D H$ & $G D H$ & $A L T$ & $G G T$ \\
\hline lanyyyyy & Liver anoxia & 90 & 25 & 25 & 25 \\
la & $\begin{array}{l}\text { Congestive cardiac } \\
\text { failure }\end{array}$ & 96 & 16 & 28 & 24 \\
2 & Generalised anoxia & 70 & 40 & 20 & 60 \\
3 & Liver disease & 65 & 80 & 70 & 90 \\
$3 \mathrm{a}$ & Alcoholic liver disease & 86 & 86 & 71 & 86 \\
$3 \mathrm{~b}$ & Carcinoma & 43 & 71 & 57 & 86 \\
\hline
\end{tabular}

\section{Stability}

Stability of ADH was a major problem: when stored at either $4^{\circ} \mathrm{C}$ or $-20^{\circ} \mathrm{C}$, on average, $20 \%$ activity was lost within 24 hours of sample collection, followed by a further $10 \%$ loss of activity each subsequent 24 hours. In contrast, samples stored at $-70^{\circ} \mathrm{C}$ remained completely stable for up to seven days.

\section{Clinical evaluation}

A detailed study was undertaken to assess the clinical use of ADH and GDH. Alcohol dehydrogenase, GDH, ALT, and GGT activities were measured on the plasma from over 200 patients with a variety of clinical disorders. From this initial group, 70 were selected for specific examination. Based on their primary clinical diagnosis, these patients were classified into one of three groups:

(i) Group 1: Liver anoxia due to centrilobular damage $(n=40)$. Patients in this category were diagnosed with the following cardiorespiratory disorders: congestive cardiac failure $(n=25)$, left ventricular failure $(n=5)$, chronic obstructive airways disease $(n=8)$, or pulmonary oedema $(n=2)$, all of which are known to cause liver anoxia and, potentially, centrilobular necrosis.

(ii) Group 2: Generalised anoxia $(\mathrm{n}=10)$ following surgery or multiple trauma.

(iii) Group 3: Liver disease $(\mathrm{n}=20)$. Patients in this group were diagnosed as having obstructive jaundice or cirrhosis $(n=5)$, viral hepatitis $(n=$ $1)$, alcoholic liver disease $(n=7)$ and carcinoma $(n=7)$.

Fig 4 shows the activities of each enzyme found in these patients. The clinical sensitivity - that is, the number of abnormal test results in those patients with disease-of each enzyme for each group and selected subgroups (those with $n>5$ ) was also documented (table 4).

Table 4 shows that $\mathrm{ADH}$ is a highly sensitive marker for liver anoxia and resultant centrilobular damage caused by cardiorespiratory disturbance (in particular congestive cardiac failure). This finding confirms and extends the preliminary work of Kato. ${ }^{4}$ Our data show that ADH is also a sensitive indicator of generalised anoxia. In terms of specific liver disease, and in particular, carcinoma of the liver, GGT was found to be superior to the other enzymes tested. GDH does not seem to have a role in detecting liver anoxia, but is at least equivalent in sensitivity to ALT as a marker for liver disease. In many cases of liver disease, an increase in ALT activity was paralleled by an increase in GDH, but the relative increase in activity - that is, the number of times greater than the top of the reference range-was far greater with GDH than with ALT. All enzymes were equally sensitive in detecting alcoholic liver disease.

\section{Conclusion}

We have developed and adapted methods for the determination of serum alcohol dehydrogenase and glutamate dehydrogenase for use with a centrifugal analyser. These enzymes were shown in a clinical study to be relatively useful markers for detection of a variety of specific liver disease states, though they were not more clinically sensitive than conventional liver enzymes such as alanine aminotransferase and, particularly, gamma-glutamyltransferase. Our findings suggest, however, that alcohol dehydrogenase may have considerable diagnostic potential in the detection of generalised anoxia and, in particular, anoxic damage to the liver caused by cardiorespiratory disorders.

We thank Dr G White for his constructive comments during the preparation of this manuscript. We are grateful to the Drug and Alcohol Services Council for their generous support.

\section{References}

I Fujisawa K, Kimura A, Minato S. Application of nicotinamideadenine dinucleotide analogs for clinical enzymology: Alcohol dehydrogenase activity in liver injury. Clin Chim Acta 1976;69:243.

2 Khayrollah AA, Al-Tamer YY, Taka M, Skursky L. Serum alcohol dehydrogenase activity in liver diseases. Ann Clin Biochem 1982;19:35-42.

3 Kato S, Ishii H, Kano S, Hagihara S, et al. Improved assay for alcohol dehydrogenase activity in serum by centrifugal analysis. Clin Chem 1984;30:1817-20.

4 Kato S, Ishii H, Kano S, et al. Alcohol dehydrogenase; a new sensitive marker of hepatic centrilobular damage. Alcohol 1985;2:35-8.

5 Jung K, Pergande M, Rej R, Schrieber G, Schimmelpfennig W. Mitochondrial enzymes in human serum: comparative determinations of glutamate dehydrogenase and mitochondrial aspartate aminotransferase in healthy persons and patients with chronic liver diseases. Clin Chem 1985;31:239-43.

6 Schellenberg F, Weill J, Lamy JN. The place of glutamate dehydrogenase in the laboratory: Detection of excessive drinkers. Ann Biol Clin 1983;41:255-62. 
7 Levy E, Ecklund P. A fully automated kinetic assay for glutamate dehydrogenase utilising a Centrifichem centrifugal analyser. Clin Chem 1979;25:1121.

$8 \mathrm{Kim}$ N, Yasmineh WG, Freier EF, Goldman AI, Theologides A. Value of alkaline phosphatase, 5'-nucleotidase, gammaglutamyltransferase, and glutamate dehydrogenase activity measurements (single and combined) in serum in diagnosis of metastasis to the liver. Clin Chem 1977;23:2034-8.

9 Harada S, Misawa S, Agarwal DP, Goedde HW. Liver alcohol dehydrogenase in the Japanese: isoenzyme variation and its possible role in alcohol intoxication. Am J Hum Genet 1980;32:8-15.

10 Bergmeyer HU, Harder M. IFCC methods for the measurement of catalytic concentrations of enzymes. Part 3. IFCC method for alanine aminotransferase. $J$ Clin Chem Clin Biochem 1980;18:521-34.

11 Szasz. G. A kinetic photometric method for serum gammaglutamyl-transpeptidase. Clin Chem 1969;15:124-36.

12 Shephard MDS, Peake MJ, Walmsley RN. Quantitative methodfor determining serum alkaline phosphatase isoenzyme activityes II. Development and clinical application of method for measuring four serum alkaline phosphatase isoenzymes. $J$ Clin Pathol 1986;39:1031-8.

Requests for reprints to: Mr MDS Shephard, Department of Biochemistry and Chemical Pathology, Flinders Medicap Centre, Bedford Park, South Australia 5042, Australia. 